\title{
Motivation and engagement of public health inspectors: a Canadian perspective for the 21st century
}

\author{
Aldo Franco
}

\begin{abstract}
Organizational leaders are measured on the success of meeting goals and objectives, and their success is greatly dependent on the level of motivation and engagement of their employees. The dynamic climate of the 21st century is forcing a shift in leadership strategies. What may have worked at one time may no longer be as effective with the current workforce. Today's labour market is dynamic and competitive, and organizational leaders are required to manage, engage, motivate, and retain a multi-generational workforce. This study reviews the literature and uses qualitative and quantitative survey responses to explore (i) the generational breakdown currently influencing the Canadian Public Health Inspection (PHI) workforce; (ii) the impact direct supervisors have on PHI motivation, engagement, and job satisfaction; and (iii) the strategies that $\mathrm{PHI}$ leaders can consider to engage their current workforce. The generational breakdown of the PHI workforce generally aligns with the current Canadian labour market. PHI motivation and engagement is influenced more from intrinsic motivators than extrinsic motivators, and managers and supervisors are a significant influencer of PHI motivation and engagement. Consequently, with today's labour market shifting, public health leaders must rethink their management and leadership strategies for success. In leading the current multi-generational workforce, it is recommended leaders take a more transformational approach to leadership versus a sole focus on the traditional transactional approach.
\end{abstract}

Key words: public sector, leadership, motivation, workforce generations, public health.

\section{Introduction}

Organizational leaders continually look for strategies to manage and lead their workforce to achieve organizational success. Despite the visions, strategic plans, and work plans, organizational success is largely dependent on the level of employee motivation and engagement (Lavigna, 2014). The focus of workplace motivation is increasingly more important in the dynamic climate of the 21 st century as leaders look to manage, engage, motivate, and retain a diverse and multi-generational workforce (Mallory, 2015). Although the research on motivation is significant and seems well documented, it has received relatively little attention in the public sector in comparison with the private sector (Wright, 2001; Bedrule-Grigorutaa, 2012).

Work motivation among public sector employees and its management is just as important, but different from that of their private sector counterparts, as it aligns more with the Public Service Motivation (PSM) theory (Perry and Wise, 1990). The public sector has unique challenges with respect to limited resources, salary increases, and limited mechanisms in reward and bonus programs (Wright, 2001; Mulhern and Massey, 2013). Consequently, the importance in the role of leadership on motivation is magnified in the public service in achieving

Corresponding author: Aldo Franco (email: AFranco@ regionofwaterloo.ca)

EHR Vol. 60(2) 34-41 organizational goals (Dess and Picken, 2000; Şen and Eren, 2012; Woodlands and Parsons, 2013; O'Connell, 2014; Perrin, 2015).

\section{Background and rationale}

Research is limited in understanding the drivers to the motivation and engagement of public sector employees, specifically to the motivation and engagement of Canadian Public Health Inspectors (PHIs). Further research must be explored to strengthen the understanding of the leaders and strategies to effectively engage and motivate the 21 st century public health inspection workforce.

With the PHI profession forming and evolving during a traditionalist time, in a very structured and regulatory environment, a gap may exist in the current motivation and engagement drivers of the 21 st century public health inspection workforce. Leaders must rethink their management and leadership strategies since what once worked may no longer apply (Jenkins, 2008).

There is a "new norm" in the Canadian workforce and for the first time it is potentially represented in the workplace by four or five generations. Therefore, there is significant opportunity to recognize and understand current strategies to enhance workers' experiences, motivation, engagement, and job satisfaction (Mulhern and Massey, 2013). The results of this 
study will provide a better understanding for leaders of what motivates and engages Canadian PHIs.

\section{Literature review}

\section{Public service motivation}

The public sector has unique challenges with respect to management, motivation, and employee performance. Research has demonstrated that public service employees have a higher need or want for intrinsic, nonmonetary incentives compared with their private sector peers (Bright, 2009). Perry and Wise (1990) pioneered the theory of PSM, which suggests individuals have a predisposition to be attracted to public service work and are motivated more by intrinsic drivers, rather than extrinsic rewards. Intrinsic preferences include motives such as task meaningfulness, doing "good" for society, professional growth, career advancement, leadership responsibility, and personal recognition (Bright, 2005; Perry et al., 2010).

\section{Generational dynamics}

For the first time in recorded history, there is the potential of five generations of workers in the workplace at the same time (Mallory, 2015; Wiedmer, 2015). Although the physical presence of the earliest generations in the workplace may have decreased, one must acknowledge their influence and presence persists.

\section{Traditionalists}

Estimated to be born between 1900 and 1945, this generation does not make up a large part of the workforce now; however, their presence and influence is evident in longstanding organizations like public service (Wiedmer, 2015). Traditionalist values are shaped by world wars, respect for authority, and conforming; they are considered the most self-sacrificing, loyal, and dedicated generation in any given workforce (Jenkins, 2008; Wiedmer, 2015). They prefer structure, are generally motivated by extrinsic and tangible rewards and recognition, and want to feel valued by their employers and supervisors (Jenkins, 2008; Mallory, 2015; Wiedmer, 2015). They typically prefer a hierarchal, top-down chain of command structure generally found in public service organizations.

\section{Baby Boomers (Boomers)}

Born between 1946 and 1964, the boomer generation grew up in a prosperous, post-war era. In many instances, they are a generation that places a very high priority on work-at times over their personal life (Jenkins, 2008). Once the biggest generational cohort, many are approaching or are in retirement, and their physical presence in the workforce is declining (Statistics Canada, 2015). Similar to the Traditionalists, there is a significant Boomer influence on current organizations.

Boomers developed under a strong Traditionalist influence, and many are currently in a position of leadership. They are very career focused and are generally motivated by extrinsic influences (Wiedmer, 2015). This competitive drive can influence some Boomers to become annoyed if they perceive their authority is being undermined or challenged (Mallory, 2015; Wiedmer, 2015). Consequently, this may result in a gap in current generational preferences and expectations.

\section{Generation X}

Born between 1965 and 1981, Generation X employees currently make up $34 \%$ of the Canadian workforce, making this group the second largest employee cohort in Canada (Statistics Canada, 2015; Wiedmer, 2015). For the most part, Gen X'ers had Boomer parents; therefore, they place a high priority on work-life balance. They are well-informed highly skilled employees and are willing to develop their skills and take on challenges (Jenkins, 2008).

In contrast to their predecessors, they question authority and are more comfortable being left to their own independence (Jenkins, 2008; Wiedmer, 2015). To get the most out of this large cohort, their leaders need to provide sound rationale behind tasks and projects and must be able to provide flexible tasks that are engaging and self-directed (Wiedmer, 2015).

\section{Millennials (Generation Y)}

Generally born between the 1980s and early 1990s, and according Statistics Canada, Millennials make up more than $37 \%$ of the Canadian workforce and have become the largest workforce generation in Canada (Figure 1) (Scott, 2015; Statistics Canada, 2015).

Millennials are technically savvy, socially connected, and have a social and global perspective on their work-life environments (Jenkins, 2008; Mallory, 2015; Wiedmer, 2015). Millennials have been described to have an entrepreneurial spirit due to their embrace of innovation, change, and technology (Gibson 2015, as cited in Wiedmer, 2015). Despite this sense of entrepreneurial spirit, Millennials share characteristics described by the PSM theory that include intrinsic preferences such as task meaningfulness, doing "good" for society, professional growth, and career advancement (Bright, 2005; Perry et al., 2010; Ng and Gossett, 2013).

Compared with their predecessors, Millennials have generally been known to have a high degree of influence and oversight from their parents; consequently, studies demonstrate "manager quality" as a highly rated motivator for Millennial employees (Ng et al., 2010). Research also shows there are three simple strategies to keep in mind when leading Millennials: $(i)$ ensure they see the meaning behind their work; (ii) keep processes,

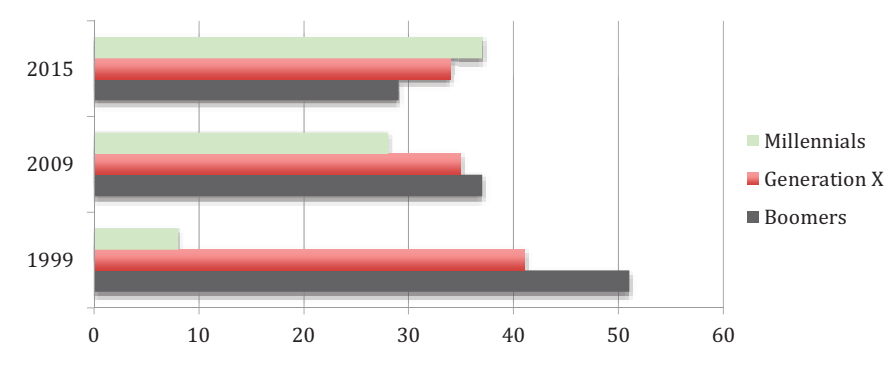

Figure 1. Canadian workforce generation breakdown. (Statistics Canada, 2015, as cited in Scott, 2015). 
systems, and technology up to date; and (iii) create a culture of trust (Coelho, 2015).

\section{Generation Z}

This is the newest generation entering the Canadian workforce and defined as anyone born after 1993 (Statistics Canada, 2015). There are many unknowns about Generation Z; however, the environment in which they have grown is well known. They have never known the world without technology and, similar to their Millennial predecessors, they continue to be tech savvy, socially connected, and are more socially and environmentally aware (White, 2015; Wiedmer, 2015). Consequently, meaningful work, being connected, innovation, and work-life balance will continue to be the signature of Generation Z. The world in which they live in continues to change rapidly; consequently, life-long learning is a critical motivator in their success (Worzel, as cited in White, 2015). Furthermore, Generation $\mathrm{Z}$ will likely not be as tied to a traditional 9-5 work day and will be far more interested in flexible work schedules or the ability to work in a virtual environment (Wiedmer, 2015).

Although these generational theories can provide general insight into the generational diversity in today's workforce, there are no absolute rules in the way people behave or what may motivate or engage them. People should not be stereotyped, magnifying the importance of modern day leaders to resist the theoretical categories and to be aware of individual needs and be flexible in their approach to motivate and retain their employees of today (Wiedmer, 2015; Espinoza, as cited in Gavett, 2015; Tulgan, as cited in Gavett, 2015).

\section{Leadership impacts}

Workforce diversity is inevitable and the success of the workforce is critical to the success of all organizations (HewinsMaroney and Williams, 2013). To deal with the inevitable shift in workforce dynamics, public sector leadership must shift their strategies to effectively lead in the 21st century (BedruleGrigorutaa, 2012; O'Connell, 2014). Leaders need to challenge the status quo, enable creativity, be innovative, and empower their employees to creatively engage the current workforce (Dess and Picken, 2000; Şen and Eren, 2012). Leadership is required to go beyond the traditional focus of a transactional leadership style. Policy and standards to meet goals in return for monetary or tangible rewards, typically found in traditional organizations, may no longer be as effective when used in isolation (Dubrin, 2010; Jogulu, 2010).

Millennials and Generation $\mathrm{Z}$ will continue to make up the majority of the labour market and challenge the status quo, and they prefer a transformational leadership style (Wiedmer, 2015). Transformational leadership focuses on an inspirational approach to have organizations reach its vision and goals. It is also described as leaders being mentors and coaches to their employees, not just managers or supervisors of work tasks (Breevaart et al., 2014; Jogulu, 2010). Transformational leadership has shown to improve transactional performance and is used by the most effective leaders (Bass, as cited in Breevaart et al., 2014; Seidman and McCauley, 2011). Additionally, research has demonstrated it takes two satisfied employees to produce the output level of one inspired employee (Garton and Makins, 2015). Effective leadership in the 21 st century will require flexibility and an ability to be outcome oriented in comparison with rigid accountability to set quantitative indicators, which are tradition in the public sector (Perrin, 2015).

\section{Research methods}

\section{Methodology}

An understanding of the perspectives of the current PHI workforce, their motivation, and the attributes that contribute to their job satisfaction were collected through a quantitative and qualitative survey. Additionally, literature were reviewed to further contribute to answering following research questions: Does the current PHI generational breakdown align with the Canadian labour market? Do direct managers and supervisors have a significant role on the motivation and engagement of PHIs? Do the motivation and engagement strategies of PHIs align with the PSM Theory?

\section{Population/sample}

The target population was the approximate $1300 \mathrm{PHI}$ members of the Canadian Institute of Public Health Inspectors (CIPHI). Direct email access to PHIs across Canada proved difficult to secure; therefore, an email was sent to the Association of Supervisors of Public Health Inspectors of Ontario listserve, with the request to distribute the survey to their respective PHI teams. Additionally, through personal contacts a "snowball" sampling technique was also used to recruit PHIs to complete the survey from areas outside of Ontario. Respondents were encouraged to recruit other PHIs to participate in the survey.

\section{Survey tool design}

A survey was created using the web-based tool SurveyMonkey. The survey was made available for 2 weeks from 15-29 February 2016. The survey began by capturing demographic data. Subsequent questions were grouped into the following categories: Job satisfaction, What motivates you? The influence of your manager or supervisor, and How do you like to be recognized at work?

Job satisfaction questions were made up of quantitative and qualitative questions. "Overall, how happy are you with your job? Why do you go to work every day?" A five-point Likert scale was used to quantitatively measure PHI perspectives. To collect qualitative data, open-text questions were asked such as: "What do you like the MOST about your work or being a PHI? What do you like LEAST about your work or being a PHI?" To measure what motivates PHIs, respondents were asked to rank their top five factors of motivation, from the list of motivation factors described in the PSM Theory (Perry and Wise, 1990), and extrinsic motivators, defined in the generational differences outlined in the literature as influencers of motivation (Ahmad and Ibrahim, 2015; Wiedmer, 2015). A six-point Likert scale was used to measure the influence of managers and supervisors on the level of PHI motivation. To measure how PHIs like to be recognized at work, a combination of a six-point Likert scale questions and ranking intrinsic and extrinsic recognition factors 
such as compensation, education and training opportunities, time off, and praise were also used (Perry and Wise, 1990; Garton and Mankins, 2015; Wiedmer, 2015). Lastly, the question, "Did we miss anything? Please share any additional drivers or factors that may influence your motivation and engagement at work," was inserted to capture any final qualitative thoughts.

\section{Findings, analysis, and evaluation}

A total of 198 survey responses were received at the end of the two-week survey period $(n=198)$. A sample size of at least 179 responses, from a potential population of an estimate of 1300 members of CIPHI, provides an $85 \%$ confidence level with a 5\% margin of error. Therefore, a sample size of 198 provides a general representation of the Canadian PHI population.

Most of the PHIs $(n=159)$ reported they work with a local public health agency $(80.3 \%)$, followed by a provincial public health agency $(16.7 \%)$, the private sector $(1.5 \%)$, retired (1.0\%), and a federal public health agency $(0.5 \%)$. The most significant response came from the province of Ontario, 170 responses (85.6\%), with limited responses from Alberta $(0.1 \%)$, British Columbia $(n=12,5.6 \%)$, and Manitoba $(n=17,8.6 \%)$.

\section{What is the generational breakdown currently influencing the Canadian Public Health Inspection workforce?}

Unlike the Canadian workforce, Generation X (40.9\%) makes up most the PHI workforce, whereas Millennials (Generation Y) make up the highest cohort of the Canadian workforce (Statistics Canada, 2015). Millennials are the second largest cohort $(26.8 \%)$ of the PHI population, followed by Boomers (31.3\%), Generation Z (0.5\%), and Traditionalists (0.5\%).

\section{Job satisfaction}

PHIs were "happy" with their job 65.96\% (124/188) of the time and 34\% (64/188) "wanted to" or "really wanted to" go to work every day. This demonstrates PHIs are generally happy at work and relatively satisfied with their career.

\section{What do you like the MOST about your work or being a PHI?}

Open text was used to solicit a qualitative perspective as to what PHIs liked most about being a PHI. The 184 responses were further categorized into high-level descriptive categories. The frequency of the response categories are illustrated in Figure 2. Almost all the comments made from this open-text box reflected intrinsic motivators, whereas "authority" and "money", reflecting extrinsic awards, were made by only three and four responders, respectively.

The following are examples of common responses provided by respondents associated with the themes outlined:

- "Helping people, seeing changes that result from my interventions, working within a science-based career; variety of work."

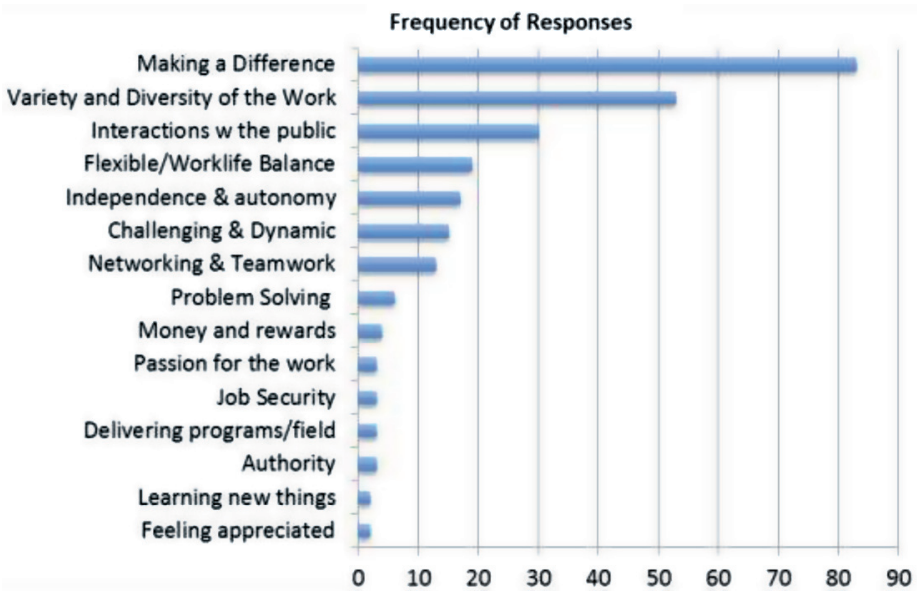

Figure 2. What do you like MOST about your work or being a PHI? $n=184$.

- "Doing something good for the community, knowing my work contributes to the prevention/reduction of illnesses/injuries."

- "Flexibility of our jobs, how we can figure out our own daily routine, the diversity of it, have office time and field time, face time with the public is great, doing something for the good of the public is also motivational."

\section{What do you like LEAST about your work or being a PHI?}

Similar comments were also grouped into high-level descriptive categories, and the frequency of the categories is illustrated in Figure 3. "Politics, conflict, administrative work, lack of recognition, and lack of support from their manager/supervisors" rounded out the top five factors PHIs like least.

The following are examples of common responses provided by respondents associated with the themes outlined:

- "Lack of support by management on multiple issues."

- "Heavy workload; losing the variety of work over the last few years; dealing with abusive operators; evaluating my work only based on the number of the inspections."

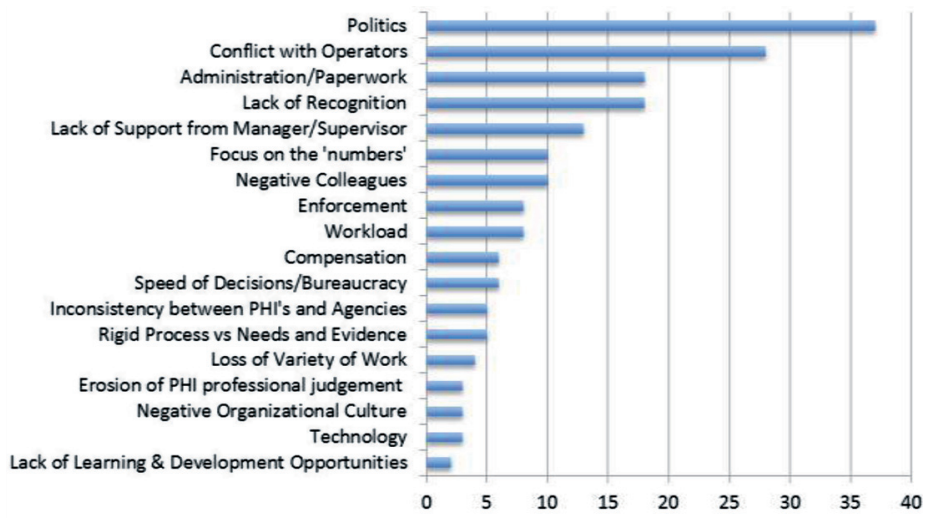

Figure 3. What do you like LEAST about your work or being a PHI? $n=188$. 
- "Moving towards a numbers-based goal (how many inspections are you doing) rather than ensuring quality."

\section{Motivation influencers}

To measure the factors that may affect the motivation of a PHI, survey respondents were asked to rank their top five influencers from a list of 10 factors. "Finding meaning in my work" was ranked first by $35 \%(62 / 176)$ of the responders. The second influencer ranked first the most often was "my direct supervisor" by $12 \%(20 / 176)$. "Financial incentives" was ranked first by responders the third highest at $8 \%(14 / 176)$. Table 1 shows how many times the motivation influencers were assigned a top five ranking by responders.

Other influencers of motivation and engagement drivers were measured through a six-point Likert scale ranking asking responders if they "strongly agree, agree, somewhat agree, somewhat disagree, disagree, or strongly disagree" to motivation statements. PHIs "strongly agreed" that an intrinsic motivator such as, "Work that gives a feeling of personal accomplishment and meaning," influenced their motivation 39.66\% $(70 / 179)$ of the time. Table 2 illustrates the breakdown of responses.

\section{Recognition}

Intrinsic motivators such as "professional development/ education/conference opportunity" were ranked as the PHIs' number one choice for recognition by 43 of the 172 responders. Although not a major influencer or method of recognition, Table 3 illustrates an extrinsic reward, such as money, is still highly valued.

\section{Open-text qualitative responses}

Sixty-seven PHIs provided additional qualitative information to the question, "Did we miss anything?" The responses were further categorized into the categories outlined in Table 4 .

Table 1. Motivation influencers receiving a top five ranking

\begin{tabular}{|l|l|c|}
\hline Rank & \multicolumn{1}{|c|}{ Motivation influencers } & $\begin{array}{c}\text { Number of top five } \\
\text { ranking responses } \\
\text { n = 176 }\end{array}$ \\
\hline 1 & $\begin{array}{l}\text { Finding meaning in my } \\
\text { work }\end{array}$ & 136 \\
\hline 2 & $\begin{array}{l}\text { Ability to be involved in } \\
\text { decisions that affect my } \\
\text { work }\end{array}$ & 124 \\
\hline 3 & $\begin{array}{l}\text { My direct manager/ } \\
\text { supervisor }\end{array}$ & 101 \\
\hline 4 & Financial incentives & 95 \\
\hline 5 & $\begin{array}{l}\text { Opportunity for career } \\
\text { growth }\end{array}$ & 89 \\
\hline
\end{tabular}

The following are further examples of some of the common responses provided, associated with the themes outlined:

- "Work being conducted by Public Health Inspectors is rarely recognized by management and/or public - this is a factor that diminishes motivation compounded with the fact that PHIs aren't recognized and (or) compensated as professionals with high levels of education and expertise."

- "My coworkers around me having a positive attitude really helps my motivation."

- "I am passionate about public health; I believe in what I do, I can't think of any other profession I would like to do."

The category of manager/supervisor contained the most comments and described lack of support or difficulties in working with their manager or supervisor. For example:

- "When your direct supervisor/manager does not engage with you regularly, does not make decisions, and passes work off, it has a negative impact on your motivation to carry out your job. Many supervisors/managers do not acknowledge the impact they can have good and bad."

- "Presently have a boss, who for me is an issue"

\section{Interpretation of the findings}

\section{Does the current PHI generational breakdown align with the Canadian labour market?}

The Baby Boomer generation that once dominated the Canadian workforce is now third in size next to the Generation $\mathrm{X}$ and the Millennial cohort (Statistics Canada, 2015). A similar trend is demonstrated in the PHI workforce; however, at this point, Generation $\mathrm{X}$ represents the largest cohort of Canadian PHIs, with the Millennial cohort second, followed by Boomers. A shift in the modern PHI workforce is evident and it is important for PHI leaders to be aware that the traditional motivation and accountability mechanisms used in the past may not be as effective as they once were (Perrin, 2015).

\section{Direct managers and supervisors have a significant role on the motivation and engagement of PHIs}

Leadership is a significant influencer on the motivation of Canadian PHIs. This study supports the leadership research and demonstrates that leadership plays an important role in motivation of PHIs. The results confirm that job satisfaction is dependent on the quality of leadership and the relationships employees have with their leaders (Finkelstein, 2015).

Transformational leadership skill development will be increasingly more important to develop and utilize as the labour market continues to shift. PHIs want to be inspired by their leadership, and they seek fulfillment in their work. Excess bureaucracy, micromanagement, cumbersome processes, layers of approvals and, as expressed by PHIs, "meeting the numbers" is not inspiring, engaging, or satisfying. 
Table 2. Motivation influencers $(n=179)$

\begin{tabular}{|l|c|c|c|c|c|c|}
\hline & $\begin{array}{c}\text { Strongly } \\
\text { agree (\%) }\end{array}$ & $\begin{array}{c}\text { Agree } \\
\text { (\%) }\end{array}$ & $\begin{array}{c}\text { Somewhat } \\
\text { agree (\%) }\end{array}$ & $\begin{array}{c}\text { Somewhat } \\
\text { disagree (\%) }\end{array}$ & $\begin{array}{c}\text { Disagree } \\
\text { (\%) }\end{array}$ & $\begin{array}{c}\text { Strongly } \\
\text { disagree (\%) }\end{array}$ \\
\hline $\begin{array}{l}\text { I need work that gives me a feeling of } \\
\text { personal accomplishment and meaning }\end{array}$ & 39.66 & 45.25 & 12.85 & 0.56 & 0.56 & 1.12 \\
\hline $\begin{array}{l}\text { Frequent contact and two-way } \\
\text { communication with my direct manager } \\
\text { or supervisor is important to me }\end{array}$ & 30.90 & 41.57 & 21.91 & 2.81 & 2.25 & 0.56 \\
\hline $\begin{array}{l}\text { Having access to updated resources and } \\
\text { tools, such as using the latest technology } \\
\text { is important to me }\end{array}$ & 25.70 & 35.70 & 30.73 & 3.91 & 3.35 & 1.12 \\
\hline $\begin{array}{l}\text { I feel that my direct manager/supervisor } \\
\text { has significant influence on my } \\
\text { motivation and engagement at work }\end{array}$ & 24.72 & 39.89 & 24.72 & 7.30 & 2.25 & 1.12 \\
\hline $\begin{array}{l}\text { I need my direct manager or supervisor to } \\
\text { recognize the work I do }\end{array}$ & 24.00 & 42.86 & 27.43 & 2.29 & 3.43 & 0.00 \\
\hline $\begin{array}{l}\text { Career enhancement and development is } \\
\text { important to me }\end{array}$ & 22.91 & 44.13 & 23.46 & 2.79 & 4.47 & 2.23 \\
\hline $\begin{array}{l}\text { My direct manager or supervisor needs to } \\
\text { provide me the opportunity to be } \\
\text { innovative and come up with new and } \\
\text { effective ideas to improve my work }\end{array}$ & 22.47 & 49.44 & 20.22 & 6.18 & 1.12 & 0.56 \\
\hline $\begin{array}{l}\text { Financial incentives motivate me more } \\
\text { than nonfinancial incentives }\end{array}$ & 12.85 & 21.79 & 26.82 & 15.08 & 18.99 & 4.47 \\
\hline $\begin{array}{l}\text { Visibility with top management is } \\
\text { important to me }\end{array}$ & 10.29 & 38.86 & 34.29 & 6.29 & 8.00 & 2.29 \\
\hline
\end{tabular}

\section{Motivation and engagement strategies of PHIs align with the PSM Theory}

As supported by the literature and PSM Theory, public service employees such as PHIs possess an increased need for intrinsic opportunities in comparison with their private sector counterparts (Bright, 2009; Perry et al., 2010; Ng and Gossett, 2013).

Table 3. Methods of recognition receiving a top five ranking

\begin{tabular}{|l|l|c|}
\hline Rank & \multicolumn{1}{|c|}{$\begin{array}{c}\text { Preferred method of } \\
\text { recognition }\end{array}$} & $\begin{array}{c}\text { Number of top five } \\
\text { ranking responses } \\
\boldsymbol{n}=\mathbf{1 7 2}\end{array}$ \\
\hline 1 & $\begin{array}{l}\text { Professional development / } \\
\text { education/conference } \\
\text { opportunity }\end{array}$ & 142 \\
\hline 2 & Money & 134 \\
\hline 3 & Time off & 117 \\
\hline 4 & $\begin{array}{l}\text { Increased job } \\
\text { responsibilities }\end{array}$ & 92 \\
\hline 5 & Thank you notes & 92 \\
\hline
\end{tabular}

Consistent with the PSM Theory, PHIs demonstrated a desire to work in the public domain in doing good for the community and society, which also aligns with the current generational dynamic (Perry et al., 2010; Wiedmer, 2015). Notwithstanding PHIs demonstrating a need for PSM and inspirational leadership, leaders must also be aware of and adjust to the fact that individuals have differing motivational and development needs (Wiedmer, 2015).

Unlike the generations that preceded them, Generation X, Millennials, and the upcoming Generation $\mathrm{Z}$ will be looking

Table 4. Additional factors that influence PHI motivation and engagement

\begin{tabular}{|l|c|}
\hline Factor & No. of replies $(\boldsymbol{n}=\mathbf{6 7})$ \\
\hline Manager/Supervisor & 19 \\
\hline Co-Workers/Team/Colleagues & 13 \\
\hline Work Environment/Culture & 11 \\
\hline Acknowledgement/Recognition & 7 \\
\hline Trust & 2 \\
\hline
\end{tabular}


for the next best opportunity. Therefore, recruitment and knowledge transfer, development, and retention will be an increasing challenges, and leaders and organizations must adapt to this at the risk of losing good employees (Boss, 2016). More than ever before, the method in which organizations treat their employees is a significant influencer of employee motivation, satisfaction, and retention.

\section{Recommendation}

PHI leaders must gain a deeper understanding of the composition of their teams and maintain flexibility in motivating and engaging PHIs in the 21st century. It is apparent the current management approach based on previous generations' desires and customs must evolve to incorporate the preferences and tendencies of today's workforce. This can be achieved by taking a more transformational approach to leadership versus a focus on the traditional transactional approach alone, congruent with the PSM Theory. This approach would be appropriate as this research demonstrated the growing Millennial and Generation $\mathrm{Z}$ cohort preference with transformational leadership and are encouraged by intrinsic motivators. Understanding the PSM theory and transformational leadership approaches will have current leaders aligning their strategies and let them connect with the shifting workforce and individual needs. As the grounded theory research and current study demonstrates, leaders should take an individual approach and gain the trust of their teams, enhance daily life (work-life balance), provide ways to be connected (physically and virtually), and demonstrate how their teams are contributing to the greater good in society.

\section{Conclusion}

The Canadian PHI workforce is in transition and is shifting into alignment with the Canadian labour market. To be successful, motivation drivers must be understood by PHI leaders, and they must rethink their management and leadership strategies, as traditional strategies may not be as effective. With the PHI profession forming and evolving during a traditionalist time, a gap may exist in the current motivation and engagement drivers of the 21 st century PHI workforce. Strategies that were effective at one time may no longer be as effective. Leaders must be aware and be flexible in their management and leadership strategies and in the way they lead their diverse teams. There is a "new norm" in the Canadian workforce, and for the first time it is potentially represented by multiple generations. Therefore, recommendations discussed provide PHI leaders a better understanding of the strategies that motivates and engages 21st century Canadian PHIs.

\section{Limitations}

Due to a lack of direct access to PHIs across the country, the "snowball" technique and distribution through the managers and supervisors professional association in Ontario were the main vehicles in getting the survey out to the PHI population. This imbalance in distribution of the survey presented a less than ideal response rate and an issue in the findings being more representative of one province compared with the others.

\section{Further research}

This is an early study measuring the general motivation and engagement drivers of PHIs in Canada, and may open the opportunity to look further at what drives Canadian PHIs. As the generational breakdown of the PHI workforce will continue to shift, and diversity of the PHI population will change, continued research is required to provide PHI leaders current and relevant knowledge, tools, and skills to maximize the opportunity for success.

\section{Acknowledgements}

Thank you to all PHIs who took the time to complete the survey and assisting with this research. I would also like to thank Dr. Kieran Mervyn from the University of Roehampton (London) for his support as my Management Research Project Faculty Supervisor.

\section{References}

Ahmad, H., and Ibrahim, B. 2015. Leadership and the characteristic of different generational cohort towards job satisfaction. Available at: http://www.sciencedirect.com/science/article/pii/S1877042815047527 [cited 2 May 2016].

Bedrule-Grigoruta, M. V. 2012. Leadership in the 21st century: Challenges in the public versus the private system. Procedia - Soc. Behav. Sci. 62. World Conference on Business, Economics and Management (BEM-2012), May 4-6, 2012, Antalya, Turkey, pp. $1028-1032$.

Boss, J. 2016. How Millennials are disrupting the workforce For the better. Forbes. Available at: http://www.forbes.com/sites/ jeffboss/2016/02/26/how-millennials-are-disrupting-the-workforcefor-the-better/\#5325c4926940 [cited 27 February 2016].

Breevaart, K., Bakker, A., Hetland, J., Demerouti, E., Olsen, O. K., Espevik, R. 2014. Daily transactional and transformational leadership and daily employee engagement. J. Occup. Organ. Psychol. 87: 138-157. doi: 10.1111/joop.12041

Bright, L. 2005. Public employees with high levels of public service motivation: Who are they, and what do they want? Rev. Public Adm. 25(2): 138-154. doi: 10.1177/0734371x04272360

Bright, L. 2009. Why do public employees desire intrinsic nonmonetary opportunities. Public Pers. Manage. 38(3): 15-37. doi: 10.1177/009102600903800302

Dess, G., and Picken, J. 2000. Changing roles: Leadership in the 21st century. Organ. Dynam. 28(3): 18-34. doi: 10.1016/s00902616(00)88447-8

Dubrin, A. J. 2010. Leadership: Research findings, practice and skills, 6th ed. Mason: Cengage Learning.

Finkelstein, S. 2015. What amazing bosses do differently. Harvard Bus. Rev. Available at: https://hbr.org/2015/11/what-amazing-bosses-dodifferently [cited 19 December 2015].

Garton, E., and Mankins, M. C. 2015. Engaging your employees is good, but don't stop there. Harvard Bus. Rev. Available at: https:// hbr.org/2015/12/engaging-your-employees-is-good-but-dont-stop-there [cited 15 March 2016]. 
Gavett, G. 2015. Generations unite. Harvard Bus. Rev. Available at: https://hbr.org/2016/01/generations-united [cited 27 January 2016].

Hewins-Maroney, B., and Williams, E. 2013. The role of public administrators in responding to the changing workforce demographics: Global challenges to the preparing a diverse workforce. Public Adm. Q. 37(3): 456-490.

Jenkins, J. 2008. Strategies for managing talent in a multigenerational workforce. Employ. Relat. Today (Wiley). 34(4): 19-26. doi: 10.1002/ert.20172

Jogulu, U. D. 2010. Culturally-linked leadership styles. Leadership Organ. Dev. J. 31(8): 705-719. doi: 10.1108/014377 31011094766

Lavigna, R. 2014. Why government workers are harder to motivate. Harvard Bus. Rev. Available at: https://hbr.org/2014/11/whygovernment-workers-are-harder-to-motivate [cited 5 October 2015].

Mallory, L. M. 2015. Factors that motivate Millenial public servants in the workplace. Walden University, Available at: http:// scholarworks.waldenu.edu/cgi/viewcontent.cgi?article=2891\&context =dissertations [cited 14 December 2015].

Mulhern, F., and Massey, J. 2013. Motivation and satisfaction among public sector employees. Available at: http://www.marketing.org/ pcontent/show/id/rr-bma-employee-engagement-for-public [cited 5 October 2015].

Ng, E. S. W., and Gossett, C. W. 2013. Career choice in Canadian public service: An exploration of fit with the Millennial generation. Public Pers. Manage. 42(3): 337-358. doi: 10.1177/ 0091026013495767

Ng, E. S. W., and Schweitzer, L., and Lyons, S. T. 2010. New generation, great expectations: A field study of the Millennial generation. J. Bus. Psychol. 25(2): 281-292. doi: 10.1007/s10869010-9159-4

O'Connell, P. K. 2014. A simplified framework for 21st century leader development. Leadership Q. 25: 183-203. doi: 10.1016/ j.leaqua.2013.06.001
Perrin, B. 2015. Bringing accountability up to date with the realities of public sector management in the 21st century. Can. Public Adm. 58(1): 183-203. doi: 10.1111/capa.12107

Perry, J. L., Hondeghem, A., and Wise, L. R. 2010. Revisiting motivational bases of public service: Twenty years of research and an agenda for the future. Public Adm. Rev. 70(5): 681-690. doi: 10.1111/j.1540-6210.2010.02196.x

Perry, J. L., and Wise, L. R. 1990. The motivational bases of public service. Public Adm. Rev. 50(3): 367-373. doi: 10.2307/ 976618

Scott, G. F. 2015. Millennials are now the biggest generation in the Canadian workforce. Canadian Business. Available at: http://www. canadianbusiness.com/innovation/the-millennial-majority-workforce/ [cited 16 December 2015].

Seidman, W., and McCauley, M. 2011. Transformational leadership in a transactional world. OD Practictioner. 43(2): $46-51$.

Şen, A., and Eren, E. 2012. Innovative leadership for the twenty-first century. Procedia - Soc. Behav. Sci. 41. pp. 1-14.

Statistics Canada. 2015. Generations in Canada. Available at: https:// www12.statcan.gc.ca/census-recensement/2011/as-sa/98-311-x/98311-x2011003_2-eng.cfm [cited 11 January 2016].

White, S. 2015. Canadian University Report 2016: The Generation Z effect. Globe and Mail. Available at: http://www.theglobeandmail. $\mathrm{com} /$ news/national/education/canadian-university-report/the-genzeffect/article26898388/ [cited 18 January 2016].

Wiedmer, T. 2015. Generations do differ: Best practices in leading traditionalists, Boomers, and Generations X,Y, and Z. Delta Kappa Gamma Bull. 82(1): 51-58.

Wright, B. E. 2001. Public-sector work motivation: A review of the current literature and a revised conceptual mode. J. Public Adm. Res. Theor. 11(4): 559-586. doi: 10.1093/oxfordjournals. jpart.a003515 